\title{
The status of Vulnerable gaur Bos gaurus and Endangered banteng Bos javanicus in Ea So Nature Reserve and Yok Don and Cat Tien National Parks, Vietnam
}

\author{
Ma N H H NGUYeN
}

\begin{abstract}
The wild buffaloes, gaur Bos gaurus and banteng Bos javanicus, are among the most threatened mammals in Vietnam but little information is available on their status and distribution. Over 2004-2007 I undertook surveys in three Vietnamese distribution strongholds of the Vulnerable gaur and Endangered banteng: Ea So Nature Reserve and Yok Don and Cat Tien National Parks. A total of 22 herds with 121 gaur and seven herds with 49 banteng were observed. Herd sizes of both species were generally lower than those recorded in Thailand and Malaysia. Most of the herds were observed in remote areas, showing that the species are probably staying away from areas with human activity. No banteng were found in Cat Tien National Park. Of the other wild buffalo species the Critically Endangered kouprey Bos sauveli and Endangered water buffalo Bubalus arnee were not observed in the three protected areas but the Near Threatened serow Capricornis milneedwardsii was occasionally observed in all three areas. Illegal hunting, habitat degradation and disturbance appear to be the most significant threats to gaur and banteng in the areas surveyed. It is essential to have effective law enforcement to eliminate human impacts on these two species, and an adequate conservation strategy to secure their long-term survival.
\end{abstract}

Keywords Banteng, Bos gaurus, Bos javanicus, gaur, herd size, hunting, trophy, Vietnam, wild buffalo.

\section{Introduction}

The gaur Bos gaurus and banteng Bos javanicus are 1 among the largest wild cattle of the family Bovidae. They range widely from mainland South Asia through South-east Asia. The gaur has been recorded in India, Bhutan, Nepal, Myanmar, Thailand, Southern China, Vietnam, Cambodia and Peninsular Malaysia, and the banteng in Myanmar, Thailand, Laos, Cambodia, Vietnam, Indonesia, Brunei and Malaysia (Dang, 1986; Corbet \& Hill, 1992; Choudhury, 2002).

In Vietnam gaur are widely distributed from north to south but occur mainly along the border with Lao PDR and

\footnotetext{
Manh Ha Nguyen Centre for Natural Resources and Environmental Studies, Vietnam National University, 19 Le Thanh Tong Street, Hanoi, Vietnam. E-mail ha.nguyenba@gmail.com

Received 12 March 2007. Revision requested 29 May 2007 Accepted 29 November 2007.
}

Cambodia (Dang, 1986; Thach \& Nguyen, 2005). Banteng, however, are limited to the south, from the northernmost areas of Kon Tum province to the southernmost parts of Binh Phuoc province (Dang, 1986; Duckworth \& Hedges, 1998; Nguyen \& Nguyen, 2005; Thach \& Nguyen, 2005). Gaur and banteng have declined in Vietnam, mostly because of illegal hunting and habitat loss (Dang, 1986; Le et al., 1997; Nguyen \& Nguyen, 2005). Consequently, only a small fraction of the gaur's former population remains in isolated areas of the northern provinces. In the southern provinces the gaur and banteng remain in some remote areas in the Central Highlands, and in the south-east and border provinces (Dang, 1986; Duckworth \& Hedges, 1998; Nguyen \& Nguyen, 2005; Thach \& Nguyen, 2005). Gaur and banteng are a high conservation priority in Annex IB (prohibiting exploitation and utilization) of the Government's wildlife protection decree. Both species are categorized as Endangered in the Vietnam Red Data Book (Ministry of Science and Technology, 2007; Government of Vietnam, 2006). In addition, the South-east Asian subspecies of banteng (Bos javanicus birmanicus) is categorized as Critically Endangered, and the South-east Asian population of gaur as Endangered (Heinen \& Srikosamatara, 1995). Globally, gaur and banteng are categorized as Vulnerable and Endangered, respectively, on the IUCN Red List (IUCN, 2007).

Recent surveys have clarified that Cat Tien and Yok Don National Parks and Ea So Nature Reserve are the most important habitats and strongholds for the gaur and banteng in Vietnam (Le et al., 1997; Duckworth \& Hedges, 1998; Murphy, 2004; Tordoff et al., 2004; Nguyen 2006a,b). I report here on studies carried out during 2004-2007 to assess the population status and distribution of the gaur and banteng, and identify the continued threats to their existence in these three protected areas.

\section{Study areas}

Yok Don National Park is in Dak Lak province of the Central Highlands (Fig. 1). With 115,545 ha of total core area it is the largest protected area in Vietnam. The majority of the Park is a mosaic of deciduous forest, semi-evergreen forest, grassland and dry-open dipterocarp forest. The Park also has a small area of evergreen forest. Topography is generally flat, at an altitude of c. $200 \mathrm{~m}$, but there are some low hills such as Yok Don Mountain (Anon., 1998a; Tordoff et al., 2004). 


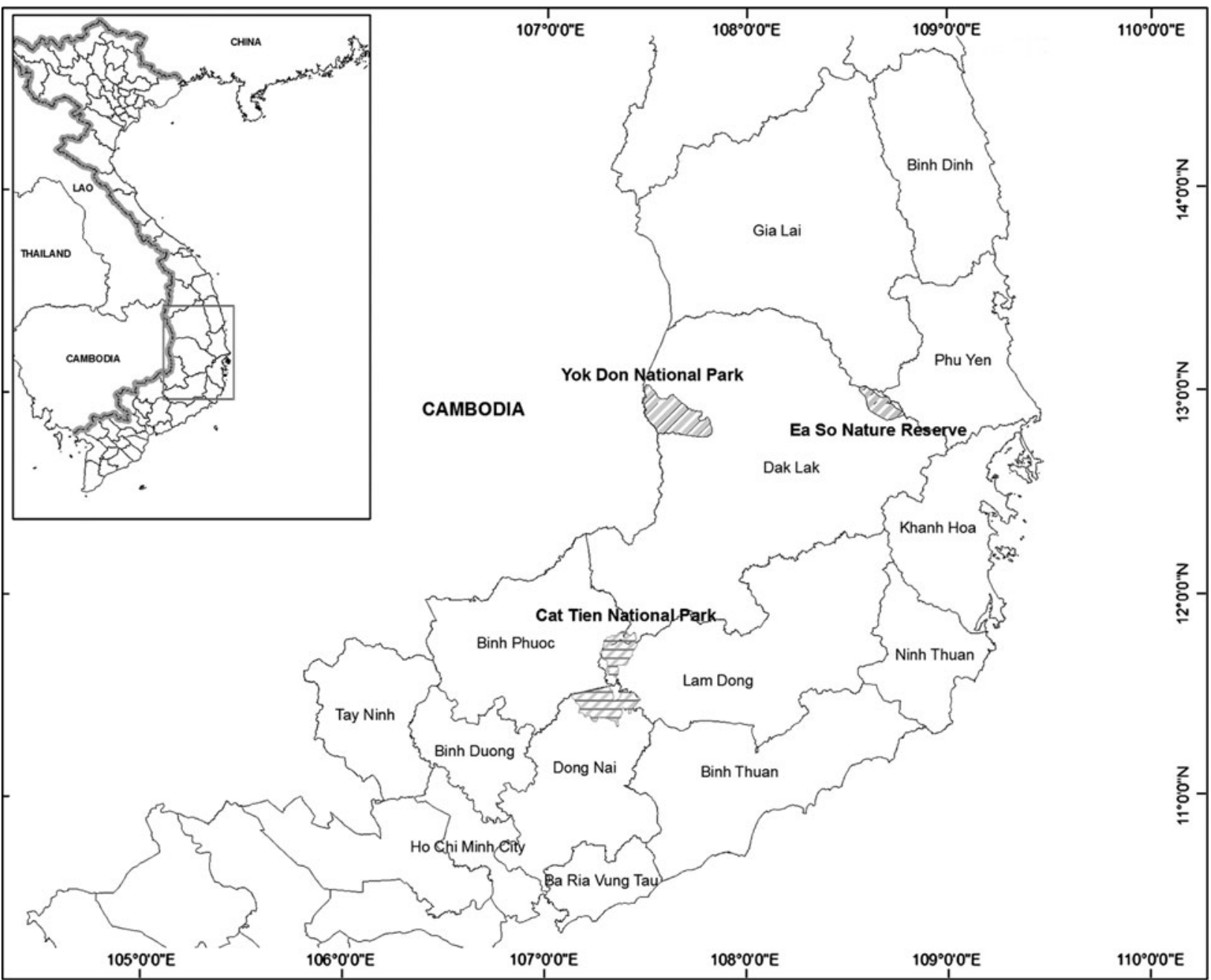

Fig. 1 Location of Ea So Nature Reserve and Yok Don and Cat Tien National Parks. The inset indicates the location of the main figure in Vietnam.

The 22,000 ha Ea So Nature Reserve is in Dak Lak province of the Central Highlands (Fig. 1). The Reserve contains evergreen, semi-evergreen and deciduous forests. Within the forest are large areas of grassland that provide an important habitat for large mammals, particularly wild cattle (Le et al., 1997; Tordoff et al., 2004). Topography is almost flat in the east, and there are relatively steep hills in the southwest and west. Altitude ranges from $140 \mathrm{~m}$ in the valley of the Ea Puich stream to $1,046 \mathrm{~m}$ on the Chu Ble Ya mountain range (Anon., 1998b; Tordoff et al., 2004).

The 70,548 ha Cat Tien National Park, among the largest protected areas in Vietnam, is in Lam Dong, Dong Nai and Binh Phuoc provinces, in the south-east (Fig. 1). The Park connects to five State Forest Enterprises (Ma Da,Vinh An, La Nga, Bu Dang and Nghia Trung), forming a large complex of lowland forest $(>100,000 \mathrm{ha})$ that is the most important habitat for animals, including wild cattle, in this area (Cat Tien National Park, 2003; Murphy, 2004; Nguyen, 2006a). The Park is divided into two sectors: Cat Loc (Lam Dong province) and Nam Cat Tien-Tay Cat Tien (Binh Phuoc and Dong Nai provinces). The Park comprises primary and secondary lowland evergreen and semi-evergreen forests, freshwater wetlands with open lakes and seasonally inundated grasslands, and bamboo forest. The topography of the park varies greatly between the sectors. The Cat Loc sector is at the southern extent of the Central Highlands, and is a mostly mountainous area with relatively steep hills (maximum altitude $659 \mathrm{~m}$ ). The Cat Tien sector is in the southern lowlands, and is characterized by low hills (maximum altitude 372 m; Cat Tien National Park, 2003; Tordoff et al., 2004).

\section{Methods}

Interviews A total of 25 forest rangers and technical officers and 32 local people in four communes in Cat Tien, two communes in Ea So and two communes in Yok Don were interviewed for information on wild cattle.

Secondary data Information on previous records of wild cattle was gathered from reports and other publications dating from 1989 onwards (Table 1). 
TAble 1 Previous gaur and banteng records in Ea So Nature Reserve and Yok Don and Cat Tien National Parks (Fig. 1).

\begin{tabular}{|c|c|c|c|}
\hline Reference & Gaur Bos gaurus & Banteng Bos javanicus & Main methods used \\
\hline \multicolumn{4}{|l|}{ Ea So Nature Reserve } \\
\hline Le et al., 1997 & At least 8 individuals & At least 17 individuals & $\begin{array}{l}\text { Secondary data review, } \\
\text { field survey }\end{array}$ \\
\hline Anon., 1998b & Presence confirmed & Presence confirmed & $\begin{array}{l}\text { Secondary data review, } \\
\text { field survey }\end{array}$ \\
\hline Duckworth \& Hedges, 1998 & Presence confirmed & Presence confirmed & Secondary data review \\
\hline Tordoff et al., 2004 & Presence confirmed & Presence confirmed & Secondary data review \\
\hline \multicolumn{4}{|l|}{ Yok Don National Park } \\
\hline Laurie et al., 1989 & Presence confirmed & At least 20 individuals & Interviews \& field survey \\
\hline Cox \& Ha, 1990 & Presence confirmed & $\begin{array}{l}3 \text { herds, at least } 30 \\
\text { individuals }\end{array}$ & Interviews \& field survey \\
\hline Dang \& Tran, 1991 & Presence confirmed & 250-370 individuals & Interviews \& field survey \\
\hline Le et al., 1997 & $\begin{array}{l}3 \text { herds, at least } 38-60 \\
\text { individuals }\end{array}$ & Presence confirmed & Interviews \& field survey \\
\hline Anon., 1998a & Presence confirmed & Presence confirmed & Interviews \& field survey \\
\hline Duckworth \& Hedges, 1998 & Presence confirmed & Presence confirmed & Secondary data review \\
\hline Tordoff et al., 2004 & Presence confirmed & Presence confirmed & Secondary data review \\
\hline \multicolumn{4}{|l|}{ Cat Tien National Park } \\
\hline Anon., 1997 & Presence confirmed & Presence confirmed & $\begin{array}{l}\text { Secondary data review \& } \\
\text { field survey }\end{array}$ \\
\hline Duckworth \& Hedges, 1998 & Presence confirmed & $\begin{array}{l}\text { Presence confirmed in } \\
\text { Cat Tien sector \& } \\
\text { provisional in Cat Loc } \\
\text { sector }\end{array}$ & Secondary data review \\
\hline Ling, 2000 & 100 individuals & No information & $\begin{array}{l}\text { Secondary data review \& } \\
\text { field survey }\end{array}$ \\
\hline Cat Tien National Park, 2003 & At least 24 individuals & No information & $\begin{array}{l}\text { Secondary data review \& } \\
\text { field survey }\end{array}$ \\
\hline Murphy, 2004 & $4-5$ herds & No information & Conservation review \\
\hline Hayes, 2004 & $\begin{array}{l}4-5 \text { herds (largest } 30 \\
\text { individuals) }\end{array}$ & Possibly extinct & $\begin{array}{l}\text { Secondary data review \& } \\
\text { field survey }\end{array}$ \\
\hline Tordoff et al., 2004 & Presence confirmed & No information & Secondary data review \\
\hline
\end{tabular}

Field surveys The number of wild cattle was estimated by direct counting from transects and observation posts. A total of 102 diurnal and nocturnal foot transects were conducted over 2004-2007 (Table 2). Diurnal transects were walked at 2-3 km per hour during 06.00-10.00 and 15.00-18.00. Nocturnal transects were walked at approximately $1 \mathrm{~km}$ per hour over 21.00-24.00 and 03.00-05.00 using searchlights and thermal binoculars. Vegetation conditions vary across the three surveyed areas. Grasslands and open forests in Ea So and Yok Don facilitated observations up to $200 \mathrm{~m}$ from the transect centre line, and $400 \mathrm{~m}$ with binoculars. In Cat Tien observation was limited in thick woodland and tall grass areas to $20-50 \mathrm{~m}$, increased to $50-100 \mathrm{~m}$ in bamboo and mixed bamboo-woodland forest (in Cat Loc sector), and to $100-400 \mathrm{~m}$ in most of the grasslands and open forests (in the southern and western sectors) of the Park. In Yok Don a total of 12 diurnal and nocturnal transects were traversed on elephants, using methods similar to those used for the transects on foot (Table 2). In addition, a total of 23 observation posts were established on hilltops and forest fire towers to provide a good view of grassland, open forest, water holes and mineral licks (Table 2). Estimation of wild cattle herd size was made by direct counting from the transects and observation posts. Because of the low density of wild cattle and the fact that most of the herds were in groups of $2-7$, there was no difficulty in making complete counts of herd size. Gaur and banteng are distinguished from each other and from any local domestic cattle by body size, horn shape and their distinctive colour. The gaur has a nearly black coat with white legs. Male gaur have a unique muscular dorsal ridge between shoulders. The banteng can be identified by its reddish coat and white patch on the rear. Banteng horns arc upwards, connected by a unique horn-like bald patch on the forehead.

\section{Results}

The surveys confirmed that gaur occur in all three areas but that banteng are only present in Yok Don and Ea So. In total 22 herds of gaur were observed, comprising 121 individuals, with a mean herd size of $5.5 \pm$ SD 5.2, and a total of seven herds of banteng, comprising 49 individuals, with a mean herd size of $7.0 \pm$ SD 1.2 (Table 3 ). 
TABLE 2 Survey effort and observations of gaur and banteng in Ea So Nature Reserve and Yok Don and Cat Tien National Parks (Fig. 1).

\begin{tabular}{|c|c|c|c|}
\hline & Ea So & Yok Don & Cat Tien \\
\hline \multicolumn{4}{|l|}{ Foot transects } \\
\hline $\begin{array}{l}\text { No. (total transect } \\
\text { length, km; effort, h) }\end{array}$ & $34(152,132)$ & $22(83,73)$ & $46(171,156)$ \\
\hline $\begin{array}{l}\text { No. of gaur herds } \\
\text { (total no. individuals) }\end{array}$ & $3(8)$ & $1(3)$ & $5(19)$ \\
\hline $\begin{array}{l}\text { No. of banteng herds } \\
\text { (total no. individuals) }\end{array}$ & $2(15)$ & $1(6)$ & 0 \\
\hline \multicolumn{4}{|l|}{ Elephant transects } \\
\hline $\begin{array}{l}\text { No. (total transect } \\
\text { length, km; effort, h) }\end{array}$ & 0 & $12(74,21)$ & 0 \\
\hline $\begin{array}{l}\text { No. of gaur herds } \\
\text { (total no. individuals) }\end{array}$ & 0 & $3(11)$ & 0 \\
\hline $\begin{array}{l}\text { No. of banteng herds } \\
\text { (total no. individuals) }\end{array}$ & 0 & $2(11)$ & 0 \\
\hline \multicolumn{4}{|l|}{ Observation posts } \\
\hline $\begin{array}{l}\text { No. of observation } \\
\text { posts (effort, h) }\end{array}$ & $8(24)$ & $6(19)$ & $9(27)$ \\
\hline $\begin{array}{l}\text { No. of gaur herds } \\
\text { (total no. individuals) }\end{array}$ & $8(24)$ & $1(4)$ & $6(67)$ \\
\hline $\begin{array}{l}\text { No. of banteng herds } \\
\quad \text { (total no. individuals) }\end{array}$ & $5(38)$ & $1(3)$ & 0 \\
\hline
\end{tabular}

\section{Ea So Nature Reserve}

Eight herds of gaur consisting of a total of 24 individuals were recorded, with an average herd size of $3.0 \pm \mathrm{SD} 0.53$, and five herds of banteng with a total of 38 individuals and an average herd size of $7.6 \pm$ SD 0.54. Gaur herd size was significantly smaller than that of banteng $(t=-14.960$, $\mathrm{df}=11, \mathrm{P}<0.001)$. Additionally, all observations of gaur herds contained $\leq 4$ individuals, which is much lower than reported in 1997 when a herd of eight was recorded (Le et al., 1997). Most of the herds of gaur and banteng (12 of 13) were recorded in the east and north-east (east bank of the Ea Puich stream). Only one herd, of gaur, was recorded on the west bank of the stream. Gaur were primarily found in deciduous and semi-evergreen forest whereas banteng were mostly found in grasslands and blocks of deciduous forest mixed with grassland. In the west and north-west the majority of natural habitat and terrain is evergreen forest on steep hills and no gaur or banteng were recorded in these areas. Unlike the gaur and banteng in Yok Don and other areas, wild cattle were relatively close to human residential areas such as ranger stations and agricultural land, probably as a result of active law enforcement activity in the nature reserve and subsequent reductions in poaching.

\section{Yok Don National Park}

Earlier records of gaur and banteng in Yok Don were rare (Table 1), with only a few observations documented from 1986 onwards (Cox \& Ha, 1990; Dang \& Tran, 1991; Le et al.,
TABLE 3 Records of gaur and banteng from our surveys during 2004-2007 in Ea So Nature Reserve and Yok Don and Cat Tien National Parks (Fig. 1).

\begin{tabular}{|c|c|c|}
\hline $\begin{array}{l}\text { Location (by } \\
\text { protected area) }\end{array}$ & $\begin{array}{l}\text { Herd } \\
\text { size }\end{array}$ & Habitat type \\
\hline \multicolumn{3}{|l|}{ Gaur (Ea So) } \\
\hline Bai me & 3 & Grassland, deciduous forest \\
\hline Doc bo tot & 4 & $\begin{array}{l}\text { Semi-evergreen \& } \\
\text { deciduous forest }\end{array}$ \\
\hline Bai Min & 3 & Semi-evergreen forest \\
\hline Trang co $\mathrm{t} 5$ & 3 & Grassland, deciduous forest \\
\hline Khu vuc 303 & 3 & Grassland, deciduous forest \\
\hline Nga ba Ea Puich & 3 & Semi-evergreen forest \\
\hline Tieu khu 628 & 3 & Grassland, deciduous forest \\
\hline Thac bay & 2 & Deciduous forest \\
\hline \multicolumn{3}{|l|}{ Gaur (Yok Don) } \\
\hline $\mathrm{Cu}$ Jut & 4 & Deciduous forest \\
\hline Dak Nor & 3 & Deciduous forest \\
\hline Dak na & 4 & Deciduous forest \\
\hline \multicolumn{3}{|l|}{ Gaur (Cat Tien) } \\
\hline Hang Doi & 4 & Bamboo, semi-evergreen forest \\
\hline Bau Trau-Dak Lo & 4 & $\begin{array}{l}\text { Bamboo, semi-evergreen } \\
\text { \& evergreen forest }\end{array}$ \\
\hline Suoi sinh & 3 & $\begin{array}{l}\text { Bamboo, semi-evergreen \& } \\
\text { evergreen forest }\end{array}$ \\
\hline Forest sector 503 & 4 & $\begin{array}{l}\text { Bamboo, semi-evergreen \& } \\
\text { evergreen forest }\end{array}$ \\
\hline Nui tuong & 17 & Bamboo, semi-evergreen forest \\
\hline Nui tuong & 4 & Grassland, semi-evergreen forest \\
\hline Bau Sau & 24 & $\begin{array}{l}\text { Seasonally inundated grasslands, } \\
\text { bamboo, semi-evergreen forest }\end{array}$ \\
\hline Doi Ho & 7 & Bamboo, semi-evergreen forest \\
\hline Bau Trau-cay dau & 5 & $\begin{array}{l}\text { Seasonally inundated grasslands, } \\
\text { semi-evergreen forest }\end{array}$ \\
\hline Dang $\mathrm{Ha}$ & 7 & Bamboo, semi-evergreen forest \\
\hline Sa Mach-Dat Do & 7 & Bamboo, semi-evergreen forest \\
\hline Total (no. of herds) & $121(22)$ & \\
\hline \multicolumn{3}{|l|}{ Banteng (Ea So) } \\
\hline Khe cat & 7 & Grassland, deciduous forest \\
\hline Trai bo 303 & 8 & Grassland \\
\hline Trang dieu hau & 8 & Grassland, deciduous forest \\
\hline Trang co $\mathrm{t} 5$ & 7 & Grassland \\
\hline Trang co lon & 8 & Grassland, deciduous forest \\
\hline \multicolumn{3}{|l|}{ Banteng (Yok Don) } \\
\hline $\mathrm{Cu}$ Jut & 5 & Deciduous forest \\
\hline Dak Ken & 6 & Deciduous forest \\
\hline Total (no. of herds) & $49(7)$ & \\
\hline
\end{tabular}

1997; Tordoff et al., 2004). Dang \& Tran (1991) reported that average gaur herd size in the Park was 5-7 and that of banteng was 20-30. During my survey three herds comprising 11 individuals of gaur and two herds comprising 11 individuals each of banteng were observed but herd size was generally lower than that reported by Dang \& Tran (1991). Four of the five herds recorded in Yok Don were in the west and south-west. The fifth was in the north-west, north of the Srepok River. All herds were in areas close to the border of Ratanakiri province, Cambodia, and concentrated in areas 
around three streams: Dak Ken, Dak Nor and Dak Na. These streams provide water for animals during the dry season when almost all other streams and waterholes dry up. Yok Don has been reported to be one of the most important areas for both gaur and banteng in Vietnam (Dang, 1986; Le et al., 1997; Tordoff et al., 2004), and the Park connects with forest areas of $\mathrm{Cu}$ Jut (Dak Nong province) and Ea Sup (Dak Lak province), which together form the largest area of habitat for the species in Vietnam (Anon., 1998a).

\section{Cat Tien National Park}

Eleven gaur herds comprising 86 individuals were observed, with an average herd size of $7.8 \pm \mathrm{SD} 6.62$, higher than recorded in Ea So or Yok Don. Two of the herds, with 17 and 24 individuals, were particularly large. The existence of these two large herds may be a result of their close proximity to the ranger stations of Nui Tuong and Bau Sau, where human impacts are minimized by effective law enforcement. In addition, these two areas have the most important grasslands, contiguous with open deciduous forest, which provide suitable habitat and browse areas for the development of the herds. No evidence was found of banteng. In addition, two other surveys (Ling, 2000; Hayes, 2004) in 2000 and 2004, also concluded that banteng were absent. However, I observed two banteng skulls (in Bau Sau and Gia Vien), and they are the last definitive information of banteng in the Park. I conclude that banteng no longer exists in this National Park. In the Cat Loc sector gaur were recorded in four main central areas: Bau Trau-Bau Dak Lo, Hang Doi, Suoi Sinh and forest sector 503. These areas are located far from the local residential and agricultural areas of Phuoc Cat II, Tien Hoang, Gia Vien and Bu Sa communes. In the Cat Tien sector gaur appear to be limited to four major areas, Bau Sau, Nui Tuong, Da Mi-Da Co and Sa Mach, in the north-east and south-west. However, one herd was isolated in Dan Ha, in the north-west. This herd and the herd in Sa Mach often move between the Park boundary and neighbouring State Forest Enterprises.

\section{Other bovid records}

I observed the serow Capricornis milneedwardsii, categorized as Near Threatened on the IUCN Red List (IUCN, 2007), on the steep hilly areas of Yok Don, Ea So and Cat Tien. However, there is no further information available on the status and local distribution of this species. It has been suggested that water buffalo Bubalus arnee, categorized as Endangered on the IUCN Red List (IUCN, 2007), occur in Yok Don and Cat Tien (Le et al., 1997; Ling, 2000; Cat Tien National Park, 2003) but I did not observe the species during the surveys. In interviews with members of local communes no reliable information was collected on the species, reiterating the findings of earlier research (Le et al., 1997; Ling, 2000;
Murphy \& Phan, 2002; Hayes, 2004). The only information was from an interview in Drang Phok village (Yok Don) indicating that there are some feral buffaloes Bubalus bubalis in the Dak Nor and Dak Na areas. Local hunters in Gia Vien commune (Cat Loc sector, Cat Tien) indicated that some domestic buffaloes were released by local people during the second Indochinese war (1964-1975) in Cat Loc. Yok Don and its adjacent areas have been considered to be within the range of the kouprey Bos sauveli, categorized as Critically Endangered on the IUCN Red List (Wharton, 1957; Dang, 1986; Laurie et al., 1989; McKinnon \& Stuart, 1989; IUCN, 2007). However, I found no information on this, species during the surveys. Other mammal surveys undertaken recently in the same area also found no evidence of this species (Le et al., 1997). It is probable that kouprey no longer exist in this Park.

\section{Threats to gaur and banteng}

Information on threats to wild cattle came from the interviews, observations of illegally killed wild cattle, and from records of illegal hunting in Ea So, Yok Don and Cat Tien. Illegal hunting appears to be the most serious threat, with trophy hunting common in the three areas. Over 2004-2006 at least one gaur and one banteng were illegally hunted in Yok Don, two banteng and four gaur in Ea So, and four gaur in Cat Tien (Nguyen, 2006b). Of these 12, only two were found with their heads, indicating trophy hunting. Additionally, gaur is a target of bushmeat hunters throughout the region, with guns and snare-traps the most common hunting methods. In Ea So at least 80 illegal handmade shotguns were confiscated by the Reserve authorities in 2005. In addition, several more guns and more than 1,000 snaretraps were confiscated in Cat Tien, Ea So and Yok Don. Habitat loss and disturbance is the second most serious threat. I observed signs of human activities such as logging, fishing and extraction of non-timber forest products during the surveys, especially in areas where the animals range and feed (such as grasslands, waterholes and large streams).

\section{Discussion}

Although herd sizes were low, at least 22 herds comprising a total of 121 gaur and seven herds with a total of 49 banteng were recorded in Yok Don and Cat Tien National Parks and Ea So Nature Reserve. Recent (Le et al., 2007) and other studies (Table 1) only confirmed the presence of a few herds in these areas, probably because these studies included little survey work and were primarily based on indirect sighting or interviewing information. It is possible that the actual number of wild cattle in Yok Don is higher than reported here because of the large size of the Park and because wild cattle commonly move across the border between Vietnam and Cambodia, thus complicating population estimates. The surveys also confirmed that banteng no longer exist in 
Cat Tien and that wild buffalo and kouprey no longer occur in Yok Don, Ea So and Cat Tien.

With an average herd size of 5.5 it appears that gaur herd size is lower than the average herd size of gaur in Thailand ( $\geq 16$ individuals) and Malaysia (1-19; Prayurasiddhi, 1997; Zainuddin, 2005). The two large herds observed in Cat Tien, in the vicinity of ranger stations, indicate that, with effective protection in combination with highly suitable habitat, herd size could approach normal size for the species in this area. The general gaur herd size in all three surveyed areas appears to be smaller than in historical records. Dang (1986) noted that average gaur herd size in Vietnam was usually 10 and, in some areas, 20-30 animals. The average recorded banteng herd size of seven is slightly lower than recorded in Thailand (6-10 in the wet season; Prayurasiddhi, 1997) and lower than recorded in Yok Don in 1991 when average herd size was 20-30 (Dang \& Tran, 1991). Small herd size may be a result of a combination of declining habitat availability and high illegal hunting pressure. In addition, habitat fragmentation has isolated a significant amount of grazing range and may also limit herd size, and there is habitat disturbance and competition with domestic livestock.

Gaur and banteng were only found in the south-west and west of Yok Don, areas that are remote and least disturbed, and in Ea So were found mainly to the east of Ea Puich stream where there are concentrations of grasslands and deciduous forest. In Cat Tien gaur were only found in the central area of the Cat Loc sector and the north-east and south-west of the Cat Tien sector, where the important waterholes of Bau Sau, Bau Trau and Nui Tuong are located. In all areas wild cattle seemed to be mostly avoiding disturbed locations such as agricultural land or inhabited areas.

Besides the direct threats of illegal hunting, habitat degradation, and disturbance there are indirect or potential threats to wild cattle in the three areas. In Ea So a new interprovince road built in 2004-2005 disturbed 800 ha of habitat, and conversion of tracks to asphalt has made a permanent division across a large part of Yok Don. The new roads also facilitate accessibility for illegal activities such as hunting and logging (Tordoff et al., 2004; Nguyen, 2006b). Additionally, competition from domestic cattle grazed illegally in the protected areas is a common problem, and diseases could pass from domestic to wild cattle. Effective law enforcement and an adequate conservation strategy are required to eliminate the impacts of both direct and indirect threats on these wild cattle species, and further research is required to provide information for long-term conservation planning.

\section{Acknowledgements}

I thank the Nagao Natural Environment Foundation and the Centre for Natural Resources and Environmental Studies, who generously funded this research, the Wild Cattle Conservation Project of the Ministry of Agriculture and Rural
Development for providing additional financial support, Cat Tien and Yok Don National Parks and Ea So Nature Reserve and their staff and rangers for providing assistance, and Herbert H. Covert, Benjamin Rawson, Quynh Bao, Thanh Hang and Eren Zink for editing and commenting on this manuscript.

\section{References}

Anon. (1997) Proposal for Support for Cat Tien National Park and Cat Loc Rhinoceros Reserve. Ministry of Agriculture and Rural Development, Hanoi, Vietnam.

Anon. (1998a) The Investment Project to Expand the Yokdon National Park. Forest Inventory and Planning Institute, Hanoi, Vietnam.

Anon. (1998b) Investment Plan for Ea So Nature Reserve. Tay Nguyen University, Buon Ma Thuot, Vietnam.

Cat Tien National Park (2003) Conservation Management and Operational Plan for Cat Tien National Park, Dong Nai, Lam Dong and Binh Phuoc Provinces, Vietnam: 2003-2008. Cat Tien National Park, Dong Nai, Vietnam.

Choudhury, A. (2002) Distribution and conservation of the gaur Bos gaurus in the Indian subcontinent. Mammal Review, 32, 199-226.

Corbet, G.B. \& Hill, J.E. (1992) The Mammals of the Indomalayan Region: A Systematic Review. Oxford University Press, Oxford, UK.

Cox, R. \& HA, D.D. (1990) Survey for Kouprey in the Yok Don Nature Reserve, Dak Lak Province, Vietnam. Unpublished Report. Kouprey Conservation Trust, Hanoi, Vietnam.

DANG, H.H. (1986) Biology and Ecology of Ungulates in Vietnam. Science and Technique, Hanoi, Vietnam.

Dang, H.H. \& Tran, A.T. (1991) Preliminary results of estimating population of banteng (Bos javanicus) in dry dipterocarp forest in Yok Don, Dak Lak province. Journal of Biology, 13, 30-36.

Duckworth, J.W. \& Hedges, S. (1998) Tracking Tigers: A Review of the Status of Tiger, Asian Elephant, Gaur, and Banteng in Vietnam, Lao, Cambodia, and Yunnan (China), with Recommendations for Future Conservation Action. WWF-Indochina Programme, Hanoi, Vietnam.

Government of Vietnam (2006) Decree No. 32/2006/ND-CP on Management of Endangered Species of Wild Fauna and Flora. Vietnamese Government, Hanoi, Vietnam.

Hayes, B. (2004) Wild Cattle Survey of Cat Tien National Park, Vietnam. Technical Report No. 47. WWF-Cat Tien National Park Conservation Project, Dong Nai, Vietnam.

Heinen, J.T. \& Srikosamatara, S. (1995) Status and protection of Asian wild cattle and buffalo. Conservation Biology, 10, 931-934.

IUCN (2007) 2007 IUCN Red List of Threatened Species. IUCN, Gland, Switzerland. Http://www.iucnredlist.org [accessed 9 April 2008].

Laurie, A., Ha, D.D. \& Pham, T.A. (1989) Survey for Kouprey (Bos sauveli) in Western Dac Lac Province, Vietnam. Unpublished Report. The Kouprey Conservation Trust, Hanoi, Vietnam.

Le, X.C., Pham, T.A., Duckworth, J.W., Vu, N.T. \& Vuthy, L. (1997) Report on Large Mammal Survey in Dak Lak Province, Vietnam. WWF Vietnam/IUCN Vietnam, Hanoi, Vietnam.

Ling, S. (2000) A Survey of Wild Cattle and Other Mammals, Cat Tien National Park, Vietnam. Technical Report No. 14. WWF-Cat Tien National Park Conservation Project, Dong Nai, Vietnam.

Ministry of Science And Technology (2007) Red Data Book of Vietnam: Part 1. Animals. Scientific and Technique, Hanoi, Vietnam.

Murphy, D. (2004) The Status and Conservation of Javan Rhinoceros, Siamese Crocodile, Phasianidae and Gaur in Cat Tien National 
Park, Vietnam. Technical Report No. 50. WWF-Cat Tien National Park Conservation Project, Dong Nai, Vietnam.

Murphy, D. \& Phan, D.T. (2002) Mammal Observations in Cat Tien National Park, Vietnam, 2002. Technical Report No. 43. WWF-Cat Tien National Park Conservation Project, Dong Nai, Vietnam.

McKinnon, J.R. \& Stuart, S.N. (1998) The Kouprey: An Action Plan for its Conservation. IUCN/SSC Asian Wild Cattle Specialist Group, Gland, Switzerland.

NGuyen, M.H. (2006a) Status and Distribution of Gaur (Bos gaurus) in Cat Tien National Park. Unpublished Report. CRES, National University, Hanoi, Vietnam.

NGuyen, M.H. (2006b) Status and Distribution of Gaur (Bos gaurus) and Banteng (Bos javanicus) in Ea So Nature Reserve, Dak Lac Province. Unpublished Report. CRES, National University, Hanoi, Vietnam.

NGuyen, M.H. \& NGuyen, H.H. (2005) Results of wild cattle (Bos spp.) survey in Binh Phuoc province. Journal of Biology, 27, $60-62$.

NGuyen, M.H. \& NGuyen, Q.T. (2004) Assessment of the status of hunting and trade in wildlife in Drang Phok village, Krong Ana communue, Buon Don district, Dak Lak province. In Proceedings of Scientific Workshop on Natural Resources and Environment 2003-2004 (eds Q.H. Truong \& B.Q. Pham), pp. 63-69. Science and Technique, Hanoi, Vietnam.

Polet, G. \& Ling, S. (2004) Protecting mammal diversity: opportunities and constraints for pragmatic conservation management in Cat Tien National Park, Vietnam. Oryx, 38, 1-11.
Prayurasiddhi, T. (1997) The ecological separation of gaur (Bos gaurus) and banteng (Bos javanicus) in Huai Kha Khaeng Sanctuary, Thailand. PhD thesis, University of Minnesota, Twin, USA.

ThaCh, M.H. \& NGUyen, M.H. (2005) Survey on wild bovines (Bovidae spp.) in Bu Gia Map National Park (Binh Phuoc province) and Nam Nung Nature Reserve (Dak Nong province). Journal of Science, 29, 103-107.

Tordoff, A.W., Tran, Q.B., Nguyen, D.T. \& Le, M.H. (eds) (2004) Sourcebook of Existing and Proposed Protected Areas in Vietnam. BirdLife International in Indochina, Hanoi, Vietnam.

Wharton, C.H. (1957) An Ecological Study of the Kouprey, Novibos sauveli (Urbain). Institute of Science and Technology, Manila, The Philippines.

Zainuddin, Z.Z. (2005) The Conservation of Malayan Gaur (Bos gaurus hubbacki) in Malaysia. Department of Wildlife and National Parks, Kuala Lumpur, Malaysia.

\section{Biographical sketch}

Manh HA NGUYen's general research interests are the biodiversity of Indochina, and in particular mammal conservation and ecology. For 10 years he has been studying threatened mammals in Vietnam, in particular langurs, gibbons, felids and wild cattle, to provide information for their conservation. He is also active in the prevention and control of illegal wildlife trade in South-east Asia, and acts as an adviser to the Vietnamese government on CITES implementation. 